\title{
Carbonic Anhydrases II, IX, and XII in Reflux Esophagitis
}

\author{
Minna Nortunen ${ }^{1,2,3} \cdot$ Nina Väkiparta ${ }^{1,2,3} \cdot$ Seppo Parkkila ${ }^{4}$ Juha Saarnio ${ }^{1,2,3} \cdot$ Heikki Huhta $^{1,2,3} \cdot$ \\ Tuomo J. Karttunen ${ }^{1,2,3}$
}

Received: 13 November 2020 / Accepted: 30 March 2021 / Published online: 30 April 2021

(c) The Author(s) 2021

\begin{abstract}
Background The pathogenesis of gastroesophageal reflux disease (GERD) has not been resolved in detail. Esophageal epithelial cells provide resistance to acidic reflux via several mechanisms, many of which involve buffering acid with bicarbonate and transporting protons. Carbonic anhydrases (CAs) are enzymes that control the acid-base balance by catalyzing the reversible hydration of carbon dioxide to produce bicarbonate and hydrogen ions.

Aims We aimed to determine the immunohistochemical expression patterns of CAII, CAIX, and CAXII in the normal esophageal squamous epithelium and in patients with GERD.

Methods We evaluated 82 biopsy samples, including 26 with a histologically normal esophagus, 26 with histologically mild esophagitis, and 30 with severe esophagitis. Expression patterns of CAII, CAIX, and CAXII in the esophageal squamous epithelium were determined by immunohistochemical staining.

Results Cytoplasmic CAII expression was predominantly detected in the upper luminal part of the squamous epithelium and was significantly $(p<0.01)$ increased in GERD. Expression of CAIX was essentially membranous. The isozyme was constantly present in the peripapillary cells. In the interpapillary areas, clustered expression was observed to emerge and increase significantly $(p<0.01)$ in esophagitis. CAXII expression was the most abundant of the isozymes and was mainly membranous. In the normal squamous epithelium, CAXII expression was confined to the basal layer; in severe esophagitis, CAXII expression increased significantly in both basal $(p<0.05)$ and superficial $(p<0.01)$ halves of the epithelium.

Conclusions We demonstrate upregulated expression of CAII, CAIX, and CAXII in GERD. The increase in expression likely contributes to esophageal epithelial resistance to acidic reflux.
\end{abstract}

Keywords GERD $\cdot$ Reflux esophagitis $\cdot$ CAII $\cdot$ CAIX · CAXII

Heikki Huhta and Tuomo J. Karttunen contributed equally as a senior author.

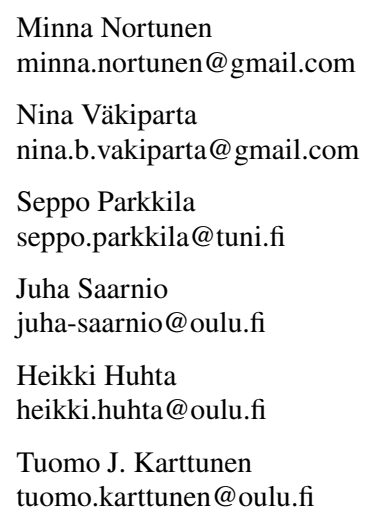

1 Cancer and Translational Medicine Research Unit, Medical Research Center Oulu, University of Oulu and Oulu University Hospital, 90014 Oulu, Finland

2 Anesthesia and Intensive Care, Research Unit of Surgery, University of Oulu, Oulu, Finland

3 Department of Surgery, Oulu University Hospital and Medical Research Center Oulu, Oulu, Finland

4 Faculty of Medicine and Health Technology, Tampere University and Fimlab Ltd, Tampere University Hospital, 33520 Tampere, Finland 


\section{Introduction}

Gastroesophageal reflux disease (GERD) has a significant worldwide prevalence of 10-30\%, with the highest popularity in the USA, parts of Europe, Latin America, and Middle East [1, 2]. Due to aging population, the prevalence and burden to economies is still increasing [2]. Of all gastrointestinal diseases, the pharmacotherapy of GERD is currently responsible for the greatest direct costs in the USA [3] and causes a significant economic burden in many European countries [4]. Developing countries in Africa, South America, and Asia offer sparse available data on GERD epidemiology or cost analyses, but it is safe to assume GERD-related costs are increasing in the emerging economies as well, even when the racial differences in the prevalence are accounted for [5]. At the same time, complications of GERD, such as Barrett's esophagus (BE) and esophageal adenocarcinoma [3, 6], appear to be increasing. Understanding the pathogenesis of reflux esophagitis is key for treatment and to prevent complications.

Esophageal epithelial cells (EECs) have been suggested to provide resistance to gastroesophageal reflux via several mechanisms, such as the capacity to buffer intra- and intercellular acidification, the efficient transport and disposal of $\mathrm{HCO}_{3}{ }^{-}$and $\mathrm{H}^{+}$and the permeability of the epithelium [7]. All of these mechanisms are potentially managed by carbonic anhydrases (CAs), catalysts of reversible $\mathrm{CO}_{2}$ hydration $\left(\mathrm{H}_{2} \mathrm{O}+\mathrm{CO}_{2} \leftrightarrow \mathrm{HCO}_{3}^{-}+\mathrm{H}^{+}\right)$. At present, 12 catalytically active isoforms of carbonic anhydrases in humans have been identified [8]. Cytosolic CAII and membrane-bound isoforms CAIX and CAXII are considered tumor-associated CAs [9], but the basic function of these highly active enzymes is related to the regulation of $\mathrm{pH}$ homeostasis and the transport of $\mathrm{CO}_{2}$ and $\mathrm{HCO}_{3}{ }^{-}[8,10]$.

To date, only fragmentary information about CAs in esophageal physiology is available. CAII, the most widely expressed CA, is present nearly throughout the gastrointestinal tract [11]. Cytosolic CAII is also expressed in EECs [12], and it has been proposed to play a role as a buffer of intracellular acidification in esophageal epithelial resistance [7, 12, 13]. CAII forms transport metabolons with sodium independent $\mathrm{Cl}^{-} / \mathrm{HCO}_{3}{ }^{-}$anion exchangers (AE1-3) and $\mathrm{Na}^{+} / \mathrm{HCO}_{3}{ }^{-}$transporters (NBCs) of the family SLC4A and the $\mathrm{Na}^{+} / \mathrm{H}^{+}$exchanger 1 (NHE-1) (SLC9A1) [14-20], all of which participate in esophageal defense [7]. Bile acids, on the other hand, have been suggested to inhibit CAII and CAIX [21]. Basolaterally located CAIX and CAXII are induced by HIF-1 $\alpha$ and hypoxia [22], but they are also expressed in normal EECs [23]. In the stomach of mice, low extracellular $\mathrm{pH}$ is an independent inducer of CAIX expression [24], and the enzyme may contribute to gastric mucosa protection by participating in tight junction maintenance [24]. CAXII has a more diverse regulatory system, which includes induction by estrogen receptor $\alpha$ $(\mathrm{ER} \alpha)[25,26]$. CAIX and CAXII have both been shown to form transport metabolons to facilitate anion transport, mainly with AE1 and AE2, but CAIX also with NBCs and NHE-1 [27-29] [30].

We have previously detailed expression of CAII, IX, and XII in normal esophageal squamous epithelium, Barrett's esophagus, and esophageal adenocarcinoma [23]. As the expression patterns and functional roles of CAs II, IX, and XII in the pathogenesis of GERD are largely unexplored, in this study, we evaluated expression of CAII, CAIX, and CAXII in the esophageal squamous epithelium in a representative series of patients with and without reflux esophagitis. We hypothesized that these enzymes are upregulated, contributing to esophageal epithelial resistance to acidinduced injury.

\section{Materials and Methods}

A series of 84 cases with esophageal archival biopsy samples were collected from the archives of the Department of Pathology, Oulu University Hospital, from 2011 to 2015. Consecutive cases were selected to obtain three subsets of patients: patients with histologically normal esophagus, histologically mild esophagitis, and histologically severe esophagitis. Information on the indications for the endoscopy and esophageal biopsies was collected from the endoscopy reports. Among subjects with histological esophagitis most had heartburn, regurgitation or dysphagia. Patients with normal esophageal histology and normal endoscopy had presented with a variety of indications such as preoperative work-up prior to bariatric surgery, or as a part of anemia or a weight-loss investigation. None of these subjects had indicated symptoms referring to GERD. Esophageal biopsies in these patients had been taken based on the consideration of the gastroenterologist or gastrointestinal surgeon performing the endoscopy, and in most cases no specific indication for taking these biopsies was recorded. No esophageal $\mathrm{pH}$ studies were performed. Esophageal biopsies were collected at the $\mathrm{Z}$-line and $+2 \mathrm{~cm}$ above. Information regarding the endoscopic degree of esophagitis according to the Los Angeles Classification [31] and the use of proton pump inhibitors 2 weeks prior to the endoscopy (PPIs) was retrieved from Oulu University Hospital medical records, including the original endoscopy reports and endoscopic footage. However, determining the LA class in sufficient accuracy in this retrospective setting was successful only in $60 \%$ of patients with GERD, mainly due to the deficient reporting of LA class in the endoscopy reports and often unrepresentative endoscopic images. Therefore, a more simplified 
grading was applied: endoscopic esophagitis was classified as mild, when erythema or edema was seen (largely corresponding to LA M), and severe in the presence of clear epithelial breaks (LA A-D). Flowchart of patient selection is presented in Fig. 1. All procedures performed in our study were in accordance with the ethical standards of the Oulu University Hospital Ethics Committee and with the 1964 Declaration of Helsinki.

The hematoxylin-and-eosin-stained sections were reevaluated according to the histological criteria of reflux esophagitis [32, 33] by an experienced gastrointestinal pathologist (TJK). The criteria included evaluation of basal cell layer hyperplasia, papillary elongation, dilatation of intercellular spaces, intraepithelial neutrophilic infiltration, intraepithelial eosinophilic infiltration, and the presence of erosion or necrosis. The features were graded on a $0-2$ scale $(0=$ absent, $1=$ mild, $2=$ severe; for neutrophils and erosion/necrosis grades were $0=$ absent and $2=$ present) [31]. The presence and severity of histological esophagitis was determined using the Global Severity (GS) score introduced by Mastracci et al. [31]. The GS score equals the mean of all histological criteria graded according to highest grade occurring in the case. In addition, GS score was assigned 2 (severe) in the presence of intraepithelial neutrophils or erosion/necrosis, even if calculated mean was less than 2 since these are considered as features of the most severe grade of histological esophagitis [31]. GS score cutoff of 0.35 has been shown to correlate well with the diagnosis of GERD based on $\mathrm{pH}$ monitoring. The group of patients with histological [32] esophagitis (GS score $\geq 0.35$ ) was divided into subgroups of mild (GS 0.35-1.49) and severe (GS 1.5-2.0) histopathological esophagitis based on the median GS score value of 1.5. The presence of lymphocytic [34], infectious and eosinophilic [35] esophagitides was excluded in reevaluation (TJK).

For immunohistochemistry, sections from formalin-fixed, paraffin-embedded specimens were subjected to high-temperature antigen retrieval in Tris-EDTA buffer for $15 \mathrm{~min}$. CA immunostaining was conducted using polyclonal rabbit anti-human CAII and CAXII sera and monoclonal antihuman CAIX antibody (M75) as described previously for polymer-based detection [36]. The antibodies have been previously characterized and are specific for each isozyme [37-39].

All immunohistochemical stainings were estimated by three independent researchers (TJK, MN, and NV). The region of esophageal squamous epithelium used for evaluation of IHC stainings was selected by an experienced pathologist (TJK) at the time of the light microscopy session for evaluation. The region with most severe histological features of GERD [32, 33] was chosen if features suggesting GERD were present in the specimen. However, necrotic squamous epithelium was not evaluated for CA expression. In other cases, any representative area of the normal squamous epithelium was scored. The other evaluators were blinded for the diagnosis and GS score of the lesion to be evaluated.

For CAII and CAXII assessment, the squamous epithelium was divided into basal and superficial halves. Both were evaluated separately for the intensity of staining $(0-3)$ and the percentage of stained cells $(0-100)$. The histoscore value is the product of the intensity and percentage for the superficial and deep halves, respectively, and the mean of these histoscores is used as the total histoscore. For CAII, a separate assessment was made for nuclear and cytoplasmic staining. For membrane-bound
Fig. 1 Flowchart of patient selection

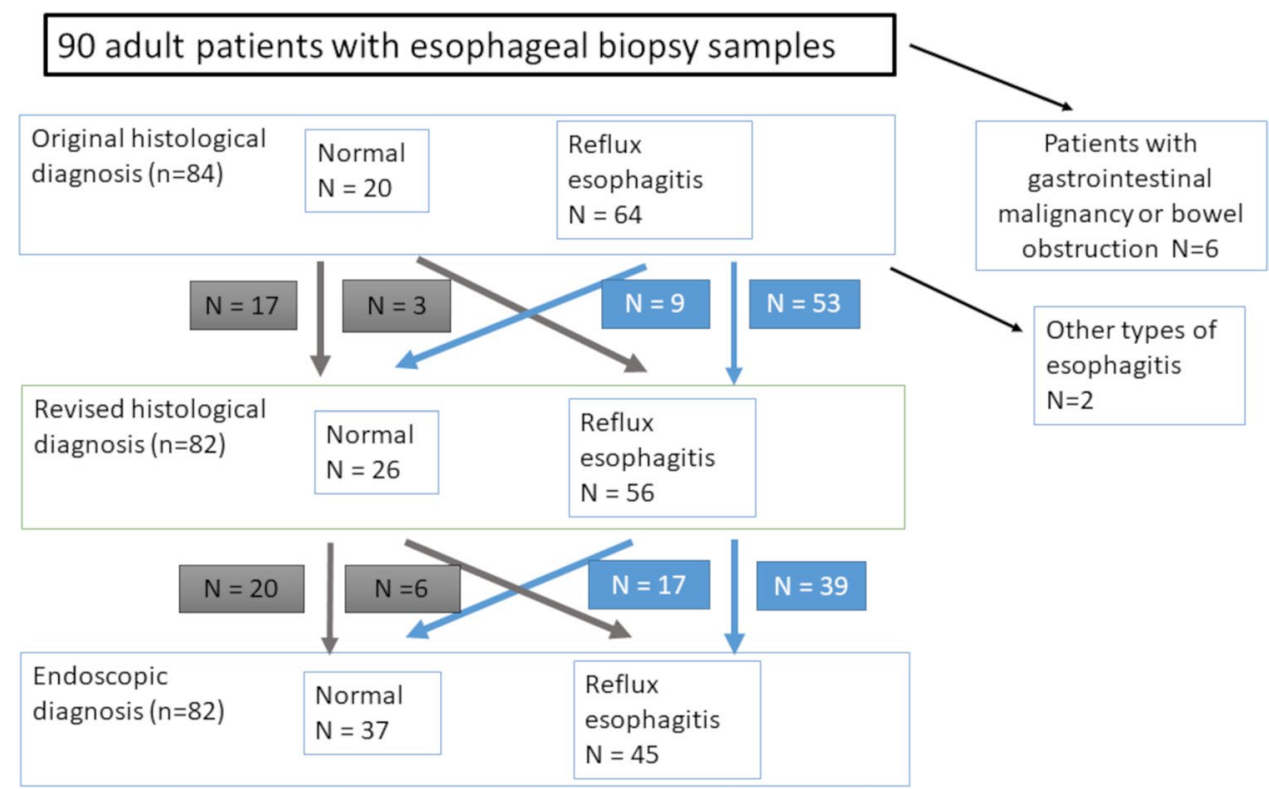


CAXII, staining was evaluated for membrane-associated and cytoplasmic expression. The CAIX expression profile differed from those of the other two isozymes studied. The majority of the CAIX staining was confined to squamous cells adjacent to subepithelial papillae and was regionally present in interpapillary squamous epithelium. CAIX expression was therefore reported by separately assessing the peripapillary and interpapillary staining. Peripapillary staining was estimated by the intensity (0-3) of the staining and the number of positive cell layers around the papilla. The peripapillary staining score was obtained by multiplying the intensity and the number of stained peripapillary cell layers. Interpapillary regions were estimated in a manner similar to the other CAs; the intensity of staining (0-3) and percentage of cells with positively stained cell membranes in the field of view were evaluated. If the individual estimates of the three observers differed by $>1$ for the intensity score, $>30 \%$ for the percentage, or $>2$ for the papillary cell layer count, consensus for the case was reached in a separate consensus meeting.

SPSS Statistics 24.0 (IBM Corp., Armonk, NY, USA) was used for statistical analyses. CAII, CAIX, and CAXII expression levels were dichotomized into two equally sized groups of low and high expression by the median value. Due to the skewed distribution and multiple testing Kruskal-Wallis with Bonferroni correction for multiple tests was used to compare expression levels between groups of histological esophagitis. We applied two-tailed Spearman's rank correlations to evaluate correlations between immunostaining intensities in basal and superficial esophageal epithelium and the degree of histological and endoscopic esophagitis. Cohen's kappa was calculated to analyze interobserver agreement, where values between $0.01-0.20$ indicate none to slight, $0.21-0.40$ fair, $0.41-0.60$ moderate, $0.61-0.80$ substantial, and 0.81-1.00 almost perfect agreement [40].

\section{Results}

Data on the patient demographics are summarized in Table 1. The final study cohort after re-evaluation with GS score included 82 patients; 26 cases with histologically normal esophagus, and 56 patients with reflux esophagitis (26 cases were scored mild and 30 severe). The diagnosis of lymphocytic esophagitis was made in two (2) cases, but zero cases of eosinophilic esophagitis were found. The median age of all patients was 58 years (range 20-94 years), with $52 \%$ women $(n=44)$ and $48 \%$ men $(n=40)$. The patients with mild reflux esophagitis were mostly women $(61 \%)$, whereas $63 \%$ of the patients with severe reflux esophagitis were men. The presence of histological and endoscopic reflux esophagitis correlated significantly $(p<0.01)$ (Table 3). Patients with lymphocytic esophagitis were not included in the final cohort of 82 patients or further analyses.

\section{CAII, CAIX, and CAXII Expression in Normal Esophagus and in Reflux Esophagitis}

Carbonic anhydrases CAII, CAIX, and CAXII were all expressed in the normal and inflamed squamous esophageal epithelium (Fig. 2; Table 2). CAII and CAIX assessments showed substantial or almost perfect interobserver agreement between researchers with kappa value ranging from 0.62 to 1.0 . For CAIX, the interobserver agreement was slightly weaker with kappa value indicating fair agreement, range $0.3-0.4$.

Table 1 Patient demographics

\begin{tabular}{|c|c|c|c|c|c|c|}
\hline \multirow[t]{2}{*}{ Characteristic } & \multicolumn{3}{|c|}{ Histological diagnosis } & \multicolumn{3}{|c|}{ Endoscopic diagnosis } \\
\hline & $\begin{array}{l}\text { Normal } \\
\text { epithelium }\end{array}$ & Mild esophagitis & $\begin{array}{l}\text { Severe } \\
\text { esophagitis }\end{array}$ & $\begin{array}{l}\text { Normal } \\
\text { endoscopy }\end{array}$ & Mild esophagitis & $\begin{array}{l}\text { Severe } \\
\text { esophagi- } \\
\text { tis }\end{array}$ \\
\hline \multicolumn{7}{|l|}{ Age } \\
\hline$<30$ & $13 / 26$ & $3 / 28$ & $3 / 30$ & $6 / 38$ & $2 / 16$ & $2 / 30$ \\
\hline $30-60$ & $13 / 26$ & $14 / 28$ & $13 / 30$ & $19 / 38$ & $5 / 16$ & $14 / 30$ \\
\hline$>60$ & $10 / 26$ & $11 / 28$ & $14 / 30$ & $13 / 38$ & $9 / 16$ & $14 / 30$ \\
\hline \multicolumn{7}{|l|}{ Sex } \\
\hline Female & $16 / 26$ & $17 / 28$ & $11 / 30$ & $27 / 38$ & $6 / 16$ & $10 / 30$ \\
\hline Male & $10 / 26$ & $11 / 28$ & $19 / 30$ & $11 / 38$ & $10 / 16$ & $20 / 30$ \\
\hline \multicolumn{7}{|l|}{ LA Class } \\
\hline Normal & $13 / 26$ & $0 / 28$ & $0 / 30$ & $12 / 38$ & $1 / 16$ & $0 / 30$ \\
\hline LA A-B & $4 / 26$ & $9 / 28$ & $5 / 30$ & $1 / 38$ & $12 / 16$ & $5 / 30$ \\
\hline LA C-D & $0 / 26$ & $0 / 28$ & $21 / 30$ & $0 / 38$ & $1 / 16$ & $20 / 30$ \\
\hline N/A & $9 / 26$ & $19 / 28$ & $4 / 30$ & $25 / 38$ & $2 / 16$ & $5 / 30$ \\
\hline
\end{tabular}

N/A, not available 


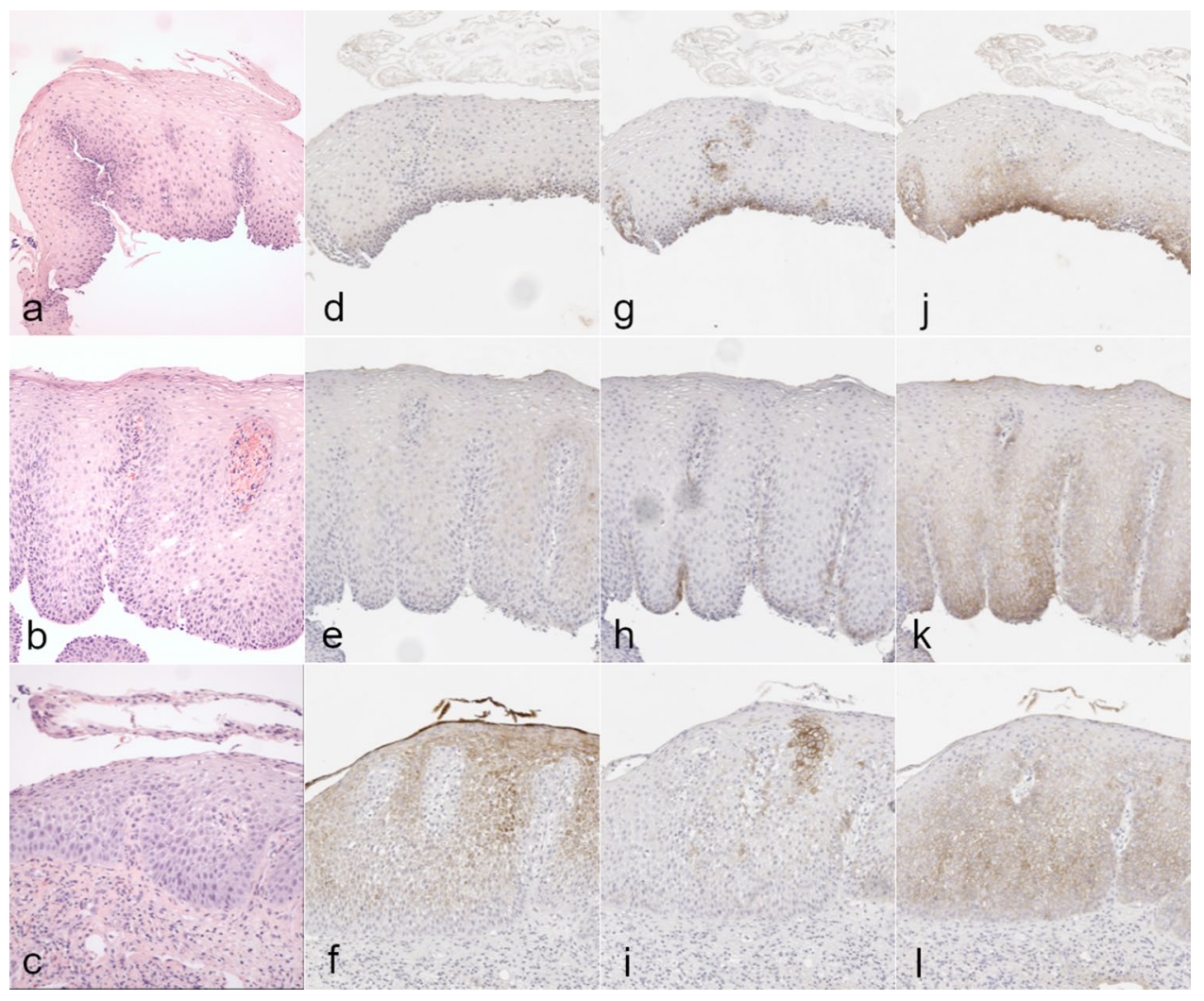

Fig. 2 Examples of typical expression patterns of CAII (d-f), CAIX $(\mathbf{g}-\mathbf{i})$, and CAXII (j-l) in the normal esophageal squamous epithelium $(\mathbf{d}, \mathbf{g}, \mathbf{j})$, and in squamous epithelium in histologically mild (e, h, k) and severe esophagitis $(\mathbf{f}, \mathbf{i}, \mathbf{l})$. For comparison, closely corresponding $\mathrm{H} \& \mathrm{E}$ stainings are presented $(\mathbf{a}-\mathbf{c})$. In normal squamous epithelium, CAII expression is mainly cytoplasmic and to lesser extent nuclear, and present in a minority of cells (d). In esophagitis (e, f), CAII expression extends throughout the epithelium with an emphasis in the superficial half and the most luminal cell layers. CAIX expression in the normal squamous epithelium (g) is mostly detectable in the cell membranes of the peripapillary cells. In mild esophagitis (h), CAIX expression remains mainly constant in the peripapillary cells and shows some increase in severe esophagitis (i). In esophagitis, groups of strongly stained cells emerge in the upper interpapillary region (i). CAXII staining is moderately strong in normal squamous epithelium, localized mainly to the plasma membrane and more evident in the basal half of the epithelium (j). In esophagitis, the expression is more intensive and extends towards the luminal surface $(\mathbf{k}, \mathbf{l})$
Table 2 Expression of CAII, CAIX, and CAXII in normal esophageal squamous epithelium and in mild and severe esophagitis

\begin{tabular}{|c|c|c|c|c|c|}
\hline \multirow[t]{2}{*}{ Protein/location } & $\begin{array}{l}\text { Normal epithe- } \\
\text { lium (histoscore) }\end{array}$ & $\begin{array}{l}\text { Mild esophagitis } \\
\text { (histoscore) }\end{array}$ & \multirow[t]{2}{*}{$p$} & $\begin{array}{l}\text { Severe esophagi- } \\
\text { tis (histoscore) }\end{array}$ & \multirow[t]{2}{*}{$p$} \\
\hline & Median (IQR) & Median (IQR) & & Median (IQR) & \\
\hline \multicolumn{6}{|l|}{ CA II } \\
\hline Basal cytoplasm & $17(6.7-43)$ & $38(12-67)$ & & $43(20-142)$ & 0.08 \\
\hline Basal nuclei & $4.4(1.1-27)$ & $22(4.4-42)$ & & $20(5.0-55)$ & 0.61 \\
\hline Superficial cytoplasm & $7.7(0.0-23)$ & $120(16-236)$ & 0.07 & $117(43-223)$ & $<0.01$ \\
\hline Superficial nuclei & $0.0(0.0-8.9)$ & $21(1.1-49)$ & & $23(0.3-53)$ & 0.12 \\
\hline \multicolumn{6}{|l|}{ CA IX } \\
\hline Peripapillary intensity & $1.0(0.0-2.0)$ & $1.5(1.0-2.0)$ & & $2.5(1.0-3.0)$ & 0.14 \\
\hline Peripapillary cells, extent & $1.0(0.0-1.3)$ & $1.2(1.0-2.0)$ & & $2.2(1.0-3.2)$ & 0.08 \\
\hline Non-papillary intensity & $1.0(0.0-1.0)$ & $1.0(0.8-1.3)$ & 1.0 & $1.0(1.0-2.3)$ & $<0.01$ \\
\hline Non-papillary histoscore & $10(0.0-10)$ & $10.0(5.8-13)$ & 1.0 & $23(10-95)$ & $<0.01$ \\
\hline \multicolumn{6}{|l|}{ CA XII } \\
\hline Basal cytoplasm & $17(8.9-20)$ & $17(13-30)$ & & $23(9.6-34)$ & 0.31 \\
\hline Basal membrane & $180(133-258)$ & $217(182-245)$ & 0.26 & $267(208-292)$ & $<0.05$ \\
\hline Superficial cytoplasm & $0.0(0.0-0.0)$ & $0.6(0.0-4.4)$ & & $0.0(0.0-1.1)$ & 0.06 \\
\hline Superficial membrane & $7.7(0.0-27)$ & $42(21-55)$ & $<0.05$ & $59(15-119)$ & $<0.01$ \\
\hline
\end{tabular}




\section{CAII}

In the normal squamocellular epithelium, the expression of CAII (Fig. 2d) was located in the cytoplasm and to a lesser extent in the nuclei and was generally faint in intensity. In histologically mild esophagitis, cytoplasmic CAII expression (Fig. 2e) increased in the superficial half of the epithelium, but the change was not statistically significant $(p=0.07)$ (Table 2). Cytoplasmic expression was further increased in severe esophagitis (Fig. 2f), where the CAII immunoreaction was significantly stronger in the superficial half compared with normal esophageal epithelium $(p<0.01)$ (Table 2, Fig. 3).

\section{CAIX}

CAIX expression was evaluated in a specific manner as the staining pattern differed distinctly from that of the other isozymes. Expression was mainly associated with cell membranes. Weak expression was occasionally observed in basal cells, mostly in single cells. Interestingly, almost constant expression was observed in the peripapillary region of the squamous epithelium; it was detectable in 1-3 layers of cells and always started at the cells adjacent to the papillary stroma (Fig. $2 \mathrm{~g}-\mathrm{i}$ ). The intensity of the staining in peripapillary cells and the number of stained cell layers were not altered in mild esophagitis compared with healthy mucosa (Fig. 2g-h), though the extent of peripapillary staining was non-significantly more abundant in severe esophagitis $(p=0.08)$ (Fig. 2i; Table 2). In addition, positive membranebound staining not related to papillae was observed, mostly in the middle and upper parts of the inflamed squamous epithelium. This interpapillary staining was present as groups of positive cells and increased significantly $(p<0.01)$ in the histoscore and intensity in severe esophagitis (Figs. 2i, 3 Table 2).

\section{CAXII}

CAXII membrane-bound expression was the most abundant of the isozymes. In normal squamous epithelium, the staining was most pronounced in the cell membranes of the basal third, with a gradual disappearance in the upper layers (Fig. 2j). Although far lesser than the membranous staining, the cytoplasmic expression showed a similar basal predominant pattern in normal epithelium (Fig. 2j). In esophagitis, expression of CAXII in the basal membranes increased significantly in the presence of severe inflammation $(p<0.05)$ (Fig. 2l). In the superficial half of the epithelium, a significant increase in the membranous immunoreaction was observed in both mild $(p<0.05)$ and severe $(p<0.01)$ esophagitis (Fig. $2 \mathrm{k}-1 ; 3$ Table 2$)$. The

Fig. 3 Total histoscore of CAII, CAIX, and CAXII in normal esophageal epithelium, mild and severe esophagitis

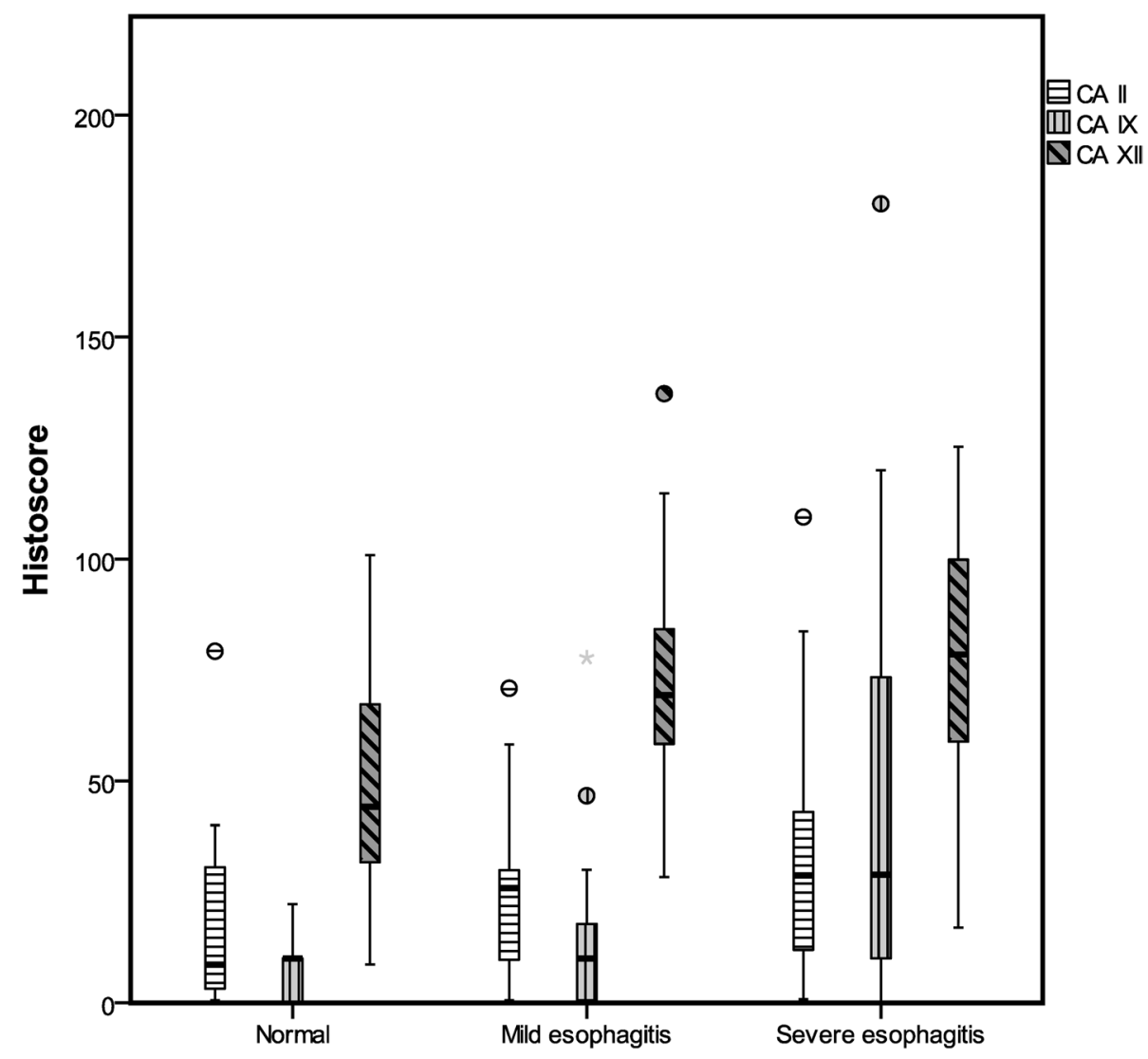


faint cytoplasmic expression of CAXII showed no changes in expression in mild or severe esophagitis.

\section{Relationship Between CAII, CAIX, and CAXII Expression and Features of Reflux Esophagitis}

The correlations between CAII, CAIX, and CAXII and the presence of histological and endoscopic esophagitis are summarized in Table 3. For CAII, both the total histoscore $(p<0.01)$ and superficial histoscore $(p<0.01)$ correlated significantly with histological esophagitis and with endoscopic esophagitis. The CAIX interpapillary histoscore showed a significant positive association $(p<0.01)$ with histological and endoscopic esophagitis. The superficial $(p<0.01)$, basal $(p<0.01)$ and total $(p<0.05)$ histoscores of CAXII correlated significantly with histological esophagitis but only superficial $(p<0.05)$ histoscore with endoscopic esophagitis. CAIX interpapillary expression and CAXII superficial expression both correlated with CAII histoscores but not with each other (Table 3).

Expression levels of CAII, CAIX, and CAXII were not related to patient sex in the total set of patients or in subgroups, nor did adjustment for sex-related differences in the severity of GERD reveal any differences (data not shown). Information regarding the use of the PPI within 2 weeks prior to endoscopy was available in $81 \%$ of the patients. The use of PPI $(n / N=32 / 82)$ did not associate with the levels of CA expression or the degree of esophagitis (data not shown).

\section{Discussion}

Our results show that CAII, IX, and XII are all upregulated in reflux esophagitis. As the essential function of CAs is to control the intra- and extracellular $\mathrm{pH}$, upregulation of expression most likely contributes to epithelial resistance to acid-related injury.

CAII expression in the superficial cytoplasm was significantly upregulated in severe GERD $(p<0.01)$ and correlated with the histopathological $(p<0.01)$ and endoscopic $(p<0.01)$ severity of esophagitis. CAII has potential functional significance in several components of esophageal epithelial resistance against acidic reflux [7]. CAII has been suggested to buffer intracellular acidosis in EECs [12, 13]. In our study, this concept was supported by a significant increase in CAII expression in the superficial, luminal parts of the epithelium in GERD. CAII forms transport metabolons with membrane-bound ion exchangers NHE-1, AEs, and NBCs [14-16, 18, 19]. All of these transporters are located in the basolateral cell walls of EECs [41-45], and they have been proposed to play a protective role in gastroesophageal reflux [46-49]. In vitro studies have shown that the activity of NHE-1, AEs, and NBCs is markedly enhanced in combination with CAII $[15,17,20]$. NHE- 1 and NBCs have also been reported to be upregulated in both BE [45] and NHE-1 in GERD without BE [50]. Although the role of acid-loading $\mathrm{Cl}^{-} / \mathrm{HCO}_{3}{ }^{-}$transporters in GERD is not as well documented, they have been shown in vitro to balance overscaled intracellular alkalization under acidic conditions, such as during GERD [42]. In summary, overexpression of
Table 3 Correlations between CAII, CAIX, and CAXII expression and esophagitis, calculated using 2-tailed Spearman correlation. Data expressed as correlation coefficient (rho) and significance $(p)$ in parentheses $0.27(p=0.027)$. Histological and endoscopic esophagitis is categorized into normal, mild, and severe

\begin{tabular}{|c|c|c|c|c|c|c|c|c|}
\hline & CAII basal & CAII superficial & CAII total & $\begin{array}{l}\text { CAIX non- } \\
\text { papillary }\end{array}$ & CAXII basal & $\begin{array}{l}\text { CAXII super- } \\
\text { ficial }\end{array}$ & CAXII total & $\begin{array}{l}\text { Endoscopic } \\
\text { esophagitis }\end{array}$ \\
\hline $\begin{array}{l}\text { Histological } \\
\text { esophagitis }\end{array}$ & $\begin{array}{l}0.2 \\
(0.10)\end{array}$ & $0.35(<\mathbf{0 . 0 1})$ & $\begin{array}{l}0.38 \\
(<\mathbf{0 . 0 1})\end{array}$ & $0.38(<\mathbf{0 . 0 1})$ & $0.33(<\mathbf{0 . 0 1})$ & $\begin{array}{l}0.45 \\
(<\mathbf{0 . 0 1})\end{array}$ & $\begin{array}{l}0.30 \\
(<\mathbf{0 . 0 5})\end{array}$ & $\begin{array}{l}0.62 \\
(<\mathbf{0 . 0 1})\end{array}$ \\
\hline CAII basal & & $0.44(<\mathbf{0 . 0 1})$ & $0.56(<\mathbf{0 . 0 1})$ & $\begin{array}{l}0.20 \\
(0.14)\end{array}$ & $0.13(0.31)$ & $0.27(<\mathbf{0 . 0 5})$ & $\begin{array}{l}0.17 \\
(0.20)\end{array}$ & $\begin{array}{l}0.06 \\
(0.65)\end{array}$ \\
\hline CAII superficial & & & $0.88(<\mathbf{0 . 0 1})$ & $0.44(<\mathbf{0 . 0 1})$ & $0.07(0.61)$ & $0.34(<\mathbf{0 . 0 1})$ & $\begin{array}{l}0.10 \\
(0.46)\end{array}$ & $\begin{array}{l}0.32 \\
(<\mathbf{0 . 0 1})\end{array}$ \\
\hline CAII total & & & & $0.35(<\mathbf{0 . 0 1})$ & $0.07(0.61)$ & $0.33(<\mathbf{0 . 0 1})$ & $\begin{array}{l}0.10 \\
(0.46)\end{array}$ & $\begin{array}{l}0.31 \\
(<\mathbf{0 . 0 1})\end{array}$ \\
\hline $\begin{array}{l}\text { CAIX non- } \\
\text { papillary }\end{array}$ & & & & & $\begin{array}{l}0.11 \\
(0.43)\end{array}$ & $\begin{array}{l}0.23 \\
(0.11)\end{array}$ & $\begin{array}{l}0.16 \\
(0.25)\end{array}$ & $\begin{array}{l}0.45 \\
(<\mathbf{0 . 0 1})\end{array}$ \\
\hline CAXII basal & & & & & & $0.48(<\mathbf{0 . 0 1})$ & $0.84(<\mathbf{0 . 0 1})$ & $\begin{array}{l}0.10 \\
(0.45)\end{array}$ \\
\hline $\begin{array}{l}\text { CAXII super- } \\
\text { ficial }\end{array}$ & & & & & & & $\begin{array}{l}0.64 \\
(<\mathbf{0 . 0 1})\end{array}$ & $\begin{array}{l}0.28 \\
(<\mathbf{0 . 0 5})\end{array}$ \\
\hline CAXII total & & & & & & & & $\begin{array}{l}0.14 \\
(0.28)\end{array}$ \\
\hline
\end{tabular}


CAII observed in reflux esophagitis likely has a protective function via enhanced intracellular acid neutralization.

The role of bile acids in regulating CAII responses during GERD is also of interest. In 1982 [51], bile acids were proposed to inhibit CAII, which was later confirmed [21, 52]. However, the antiulcerogenic effect of azetazolamide, a CA inhibitor, appears to not mediate CA inhibition in the stomach of rats [53]. The cumulative effect of bile and acid reflux on CAII expression and activity still requires further study.

Expression of CAIX in esophageal squamous epithelium was present in two main subpopulations of squamous cells, namely in layers $1-3$ of peripapillary cells, and clusters of cells within the middle and upper third of the epithelium. CAIX was also only occasionally present in single basal cells outside the peripapillary region. Peripapillary expression and CAIX expression in the odd, positive basal cells, were largely constant and showed no change in esophagitis. Such absence of increase in expression in esophagitis does not support a role of CAIX as a basal cell marker. It is of interest that esophageal stem cells may locate in the peripapillary region [54] which, however, is still a matter of controversy. In the human intestine, CAIX expressing cells in the crypt bases $[55,56]$, share both the location and morphological features of stem cells [55, 57], suggesting that CAIX might be associated with stemness in at least some epithelial types. Whether the CAIX labeled peripapillary squamous cell population is functionally specific, needs additional studies.

The second subpopulation of CAIX-expressing cells comprised clusters of squamous epithelial cells mainly in the middle and upper layers of epithelium and mostly not in contact with the papillae or basal cell layer. These clusters were rare in normal epithelium and in mild esophagitis, but this expression pattern significantly increased in severe esophagitis $(p<0.01)$. Mechanisms for the increased expression remain speculative. Main inducers of CAIX are hypoxia via HIF- $1 \alpha$ activation, and MAPK activation. Acid-induced MAPK response may occur in GERD [58]. In general, hypoxia worsens inflammation via HIF-1 $\alpha$ downstream effects [59], but the involvement of HIF- $1 \alpha$ in esophagitis is not clear [58, 60]. In GERD, HIF- $2 \alpha$ but not HIF- $1 \alpha$ was induced in the squamous epithelium, although not significantly [60]. One animal study, with an experimental reflux esophagitis model, has found a significant upregulation of HIF- $1 \alpha$ in reflux esophagitis [61]. In our study, the anatomical localization of the cell clusters with increased CAIX expression was in a region distant from mucosal blood vessels in either papillae or beneath the non-papillary region of basal cells. Such specific location might harbor focal epithelial hypoxia and thereby increased CAIX expression. Mechanisms, why the uppermost squamous cells above the CAIX positive clusters remained negative, could be related with the lower oxygen demand in the fully maturated cell layer [62]. Furthermore, heavy epithelial proliferation contributing to both histological severity of inflammation and oxygen demand [62] might explain the abundance of CAIX expression in severe esophagitis.

Considering the functional role of CAIX overexpression, Li et al. [24] demonstrated how CAIX knockout gastric epithelial cells fail to maintain intracellular $\mathrm{pH}$ via claudin-18 downregulation, which leads to tight junction failure. Claudin-18 has also been proposed to act as the dominant tight junction protein in $\mathrm{BE}$ and to contribute to the more evolved acid resistance in BE compared with healthy esophageal mucosa [63]. The upregulation of CAIX in reflux esophagitis and further in BE [23], in combination with the characteristic disruption of cell-to-cell junctions in GERD [64], supports the suggested role of CAIX in tight junction maintenance. CAIX is also reported to function as a component of membrane-bound transport metabolons with NBCs [29], NHE-1 [30], and AEs 1-3 [27], providing an approximately $30 \%$ increase in the function of the transporters. As described in connection with CAII, NHE-1 expression has been shown induced in GERD [50]. NHE-1 and NBCs have been reported upregulated in patients with BE [45]. Similarly, in rat EECs, AEs function in co-operation with acid extruders and counteract excessive alkalinization of $\mathrm{pH}_{\mathrm{i}}$ during acidic reflux [42]. We conclude that the increased interpapillary CAIX expression in reflux esophagitis likely contributes to esophageal defense against acid via several mechanisms.

Expression of CAXII in the squamous esophageal epithelium was most extensive and intensive in the cell membranes of the basal layer, with no change in mild reflux esophagitis, but a significant increase in severe esophagitis $(p<0.05)$. Expression of CAXII was significantly increased in the membranes of the superficial layer in mild $(p<0.05)$ and severe esophagitis $(p<0.01)$. CAXII has been reported to activate AE2 and to coreside at the basolateral membrane to form a transport metabolon in HeLa cells [28]. CAXII upregulation likely leads to more efficient epithelial $\mathrm{pH}$ control through collaboration with the ion transporter, as suggested for CAII and CAIX. The CAXII expression pattern also shows an interesting aberration compared with the immunoreactions of other CAs in esophagitis, as shown here and in BE in our previous study [23]. Strong CAXII expression in the squamous epithelium in GERD is almost completely abolished in esophageal metaplastic columnar epithelium [23], implicating selective inhibition of CAXII along with columnar metaplasia; further studies are clearly needed. Finally, as male sex is associated with GERD and evidence exists of ER $\alpha$-related regulation of CAXII expression [25, 65], we analyzed the relationship of sex and CAXII expression in the esophagus. No association between sex and CAXII or the other CAs was observed. 
In addition to correlating with histological and endoscopic esophagitis, the expression levels of CAII, CAIX, and CAXII in esophageal squamous epithelium intercorrelated significantly (Table 3 ), suggesting shared regulatory mechanisms. However, although statistically significant, several correlation coefficients were rather low, likely related with both pre-analytical issues, such as somewhat inconsistent fixation conditions of the specimens, analytical factors related with IHC, and heterogeneity of the actual disease process. Additionally, histopathological and endoscopic scores may not represent biologically the most relevant grades of severity. Considering alternative explanations, it seems that the variables representing basal half of the epithelium showed the weakest significant correlations (Table 3). We speculate that expression patterns in the basal half could represent more constitutive expression levels, while those in the superficial half may represent direct reactions to GERD and possibly shared regulation in reflux esophagitis. Our results suggest that in reflux esophagitis all three CA isozymes contribute to the response. CAII reaction is dominant in the luminal part of the epithelium, CAXII is strongly expressed in the basal half, but expression in the superficial half is a part of the response. CAXI responds as intense clusters between the elongated papillae. Thus, CAs upregulation seems to synergistically cover the full thickness of the esophageal epithelium and the cumulative contribution to the esophageal defence mechanisms is probably significant. Considering possible shared regulatory mechanisms, we found that expression of the CAs studied correlated with the thickness of basal cell zone, a feature suggesting a link with the regulation of cell proliferation. However, predominant location of the upregulation in the upper half of the squamous epithelium indicates involvement of additional regulatory networks. The identification of the regulatory feedback between human CAs will need considerable research attention in the future.

The limitations of our study include the retrospective design, with no information about $\mathrm{pH}$ monitoring or patient symptoms available and difficulties in obtaining reliable endoscopic grading. Regardless, in our study setting, the crucial requirement was not for every patient to meet the full diagnostic criteria designed for clinical decision making; instead, we sought to merely investigate samples that with sufficient accuracy represent epithelial injury caused by acidic reflux and samples without such injury. Diagnosis of the injury was based on a well-characterized histological multifactorial scoring system and a cutoff value able to detect most cases with acid reflux [32], as shown by $\mathrm{pH}$ monitoring [66]. In addition, specific types of non-reflux esophagitis were excluded based on a careful histopathological analysis. Secondly, the IHC assessment might include bias. During evaluation of IHC staining, an experienced pathologist selected in each specimen an area of squamous epithelium in full thickness with either normal tissue, or region showing the most severe histopathological features of reflux esophagitis. Although the severity grade was not indicated to other evaluators, it is obvious that it was not possible to blind the evaluators from the features indicating the presence or severity of esophagitis. This phenomenon is methodologically characteristic to IHC studies in general. The degree of interobserver agreement in IHC assessments in our study, however, ranged from fair to almost perfect. Thirdly, we aimed to study the effect of sex by obtaining similar numbers of male and female patients, but the final distribution of esophagitis with different grades was not even; indeed, males more often had severe esophagitis. Therefore, the detection of any independent role of sex regarding the expression of the studied markers awaits additional studies.

The results of the present study have both research-related and potential clinical implications. Our study was designed as a pilot study and prospective replication studies including $\mathrm{pH}$ measurements are needed to confirm the findings and to examine the possible role of CAs as biomarkers of different degrees of reflux esophagitis. CAII has been proposed a function in nociception [67], and therefore, its possible correlation to patient heartburn would be of particular interest. CAII could potentially serve as a biomarker for NERD. Considering the presumed protective effects of increased CA expression, there is clearly a need for experimental evidence of those responses and perhaps studies designed to disclose the regulatory mechanisms of CA expression in EECs. Hypothetically, it could be possible to use various activators of CAs to enhance the potentially protective enzymatic effects without affecting the enzyme levels. There are several compounds that are known to activate CAs, including serotonin reuptake inhibitors (fluoxetine, sertraline, and citalopram) [68], 1-histidine and its derivatives [69], and carnosine derivatives [70]. So far there is no evidence on their role in the treatment of reflux esophagitis.

In conclusion, CAII, CAIX, and CAXII are all upregulated in reflux esophagitis. Functionally, they likely contribute to esophageal defense against acid reflux. Moreover, expression levels of CAII, IX, and XII showed positive correlations, suggesting shared regulatory factors.

Acknowledgments We thank Ms. Aulikki Lehmus for skillful technical assistance in performing the immunostaining experiments. We also thank Drs. Silvia Pastorekova, Abdul Waheed and William S. Sly for providing the anti-CAIX and anti-CAXII antibodies used for the immunostaining.

Author's contribution TK and MN designed the study; the data were acquired by MN, NV, and TK and analyzed by TK, MN, NV, and $\mathrm{HH}$. MN, TK, SP, HH, and JS contributed to the interpretation of the data. MN wrote the manuscript which was reviewed and edited by all the other authors. All authors have approved the final version to be published and have agreed to be accountable for every aspect of the work. 
Funding Open access funding provided by University of Oulu including Oulu University Hospital. This study was funded by Mary and Georg C. Ehrnroots Foundation (HH) and Thelma Mäkikyrö Foundation $(\mathrm{HH})$.

Availability of data and materials The datasets generated during and/or analyzed during the current study are available from the corresponding author on reasonable request.

\section{Declarations}

Conflict of interest The authors declare that they have no conflicts of interest.

Ethical approval All procedures performed in our study were in accordance with the ethical standards of the institutional research committee and with the 1964 Declaration of Helsinki and its later amendments. For this type of study, formal consent is not required. Regional Ethical Committee Approval No: EETTMK: 81/2008. Valvira (National Licensing and Supervising Agency for Social Affairs and Health) Approval No: 10832/06.01.03.01/2014. This article does not contain any studies with animals performed by any of the authors.

Open Access This article is licensed under a Creative Commons Attribution-NonCommercial 4.0 International License, which permits any non-commercial use, sharing, adaptation, distribution and reproduction in any medium or format, as long as you give appropriate credit to the original author(s) and the source, provide a link to the Creative Commons licence, and indicate if changes were made. The images or other third party material in this article are included in the article's Creative Commons licence, unless indicated otherwise in a credit line to the material. If material is not included in the article's Creative Commons licence and your intended use is not permitted by statutory regulation or exceeds the permitted use, you will need to obtain permission directly from the copyright holder. To view a copy of this licence, visit http://creativecommons.org/licenses/by-nc/4.0/.

\section{References}

1. Eusebi LH, Ratnakumaran R, Yuan Y, Solaymani-Dodaran M, Bazzoli F, Ford AC. Global prevalence of, and risk factors for, gastro-oesophageal reflux symptoms: a meta-analysis. Gut 2018;67:430-440. https://doi.org/10.1136/gutjnl-2016-313589.

2. GBD 2017 Gastro-oesophageal Reflux Disease Collaborators. The global, regional, and national burden of gastro-oesophageal reflux disease in 195 countries and territories, 1990-2017: A systematic analysis for the global burden of disease study 2017. Lancet Gastroenterol Hepatol. 2020;5:561-581

3. Rubenstein JH, Chen JW. Epidemiology of gastroesophageal reflux disease. Gastroenterol Clin North Am 2014;43:1-14. https://doi.org/10.1016/j.gtc.2013.11.006.

4. Willich SN, Nocon M, Kulig M et al. Cost-of-disease analysis in patients with gastro-oesophageal reflux disease and barrett's mucosa. Aliment Pharmacol Ther 2006;23:371-376.

5. Goh KL. Changing epidemiology of gastroesophageal reflux disease in the Asian-pacific region: an overview. J Gastroenterol Hepatol 2004;19:S22-S25.

6. Runge TM, Abrams JA, Shaheen NJ. Epidemiology of barrett's esophagus and esophageal adenocarcinoma. Gastroenterol Clin North Am 2015;44:203-231.
7. Orlando RC. The integrity of the esophageal mucosa. Balance between offensive and defensive mechanisms. Best Pract Res Clin Gastroenterol 2010;24:873-882. https://doi.org/10.1016/j. bpg.2010.08.008.

8. Supuran CT. Structure and function of carbonic anhydrases. Biochem J 2016;473:2023-2032. https://doi.org/10.1042/BCJ20 160115.

9. Pastorekova S, Parkkila S, Pastorek J, Supuran CT. Carbonic anhydrases: current state of the art, therapeutic applications and future prospects. J Enzyme Inhib Med Chem 2004;19:199-229. https:// doi.org/10.1080/14756360410001689540.

10. Supuran CT. Carbonic anhydrases and metabolism. Metabolites 2018;8:25. https://doi.org/10.3390/metabo8020025.

11. Kivela AJ, Kivela J, Saarnio J, Parkkila S. Carbonic anhydrases in normal gastrointestinal tract and gastrointestinal tumours. World J Gastroenterol. 2005;11:155-163. https://doi.org/10.3748/wjg. v11.i2.155.

12. Christie KN, Thomson C, Xue L, Lucocq JM, Hopwood D. Carbonic anhydrase isoenzymes I, II, III, and IV are present in human esophageal epithelium. J Histochem Cytochem 1997;45:35-40. https://doi.org/10.1177/002215549704500105.

13. Orlando RC. Review article: Oesophageal mucosal resistance. Aliment Pharmacol Ther 1998;12:191-197. https://doi.org/10.1046/j. 1365-2036.1998.00308.x.

14. Vince JW, Reithmeier RA. Identification of the carbonic anhydrase II binding site in the $\mathrm{cl}(-) / \mathrm{HCO}(3)(-)$ anion exchanger AE1. Biochemistry. 2000;39:5527-5533.

15. Li X, Alvarez B, Casey JR, Reithmeier RA, Fliegel L. Carbonic anhydrase II binds to and enhances activity of the na+/H+ exchanger. J Biol Chem. 2002;277:36085-36091.

16. Bonar PT, Casey JR. Plasma membrane $\mathrm{cl}^{-} / \mathrm{HCO}_{3}{ }^{-}$exchangers: structure, mechanism and physiology. Channels (Austin) 2008;2:337-345.

17. Sterling D, Reithmeier RA, Casey JR. A transport metabolon, functional interaction of carbonic anhydrase II and chloride/bicarbonate exchangers. J Biol Chem 2001;276:47886-47894.

18. Gross E, Pushkin A, Abuladze N, Fedotoff O, Kurtz I. Regulation of the sodium bicarbonate cotransporter kNBC1 function: Role of asp(986), asp(988) and kNBC1-carbonic anhydrase II binding. $J$ Physiol 2002;544:679-685.

19. Loiselle FB, Morgan PE, Alvarez BV, Casey JR. Regulation of the human NBC3 na+/HCO3- cotransporter by carbonic anhydrase II and PKA. Am J Physiol Cell Physiol 2004;286:C1423-C1433.

20. Becker HM, Deitmer JW. Carbonic anhydrase II increases the activity of the human electrogenic na+/HCO3- cotransporter. $J$ Biol Chem 2007;282:13508-13521.

21. Nocentini A, Bonardi A, Gratteri P, Cerra B, Gioiello A, Supuran CT. Steroids interfere with human carbonic anhydrase activity by using alternative binding mechanisms. J Enzyme Inhib Med Chem 2018;33:1453-1459. https://doi.org/10.1080/14756366. 2018.1512597.

22. Wykoff CC, Beasley NJ, Watson PH et al. Hypoxia-inducible expression of tumor-associated carbonic anhydrases. Cancer Res 2000;60:7075-7083.

23. Nortunen M, Huhta $\mathrm{H}$, Helminen $\mathrm{O}$ et al. Carbonic anhydrases II, IX, and XII in barrett's esophagus and adenocarcinoma. Virchows Arch 2018;473:567-575. https://doi.org/10.1007/ s00428-018-2424-z.

24. Li T, Liu X, Riederer B et al. Genetic ablation of carbonic anhydrase IX disrupts gastric barrier function via claudin-18 downregulation and acid backflux. Acta Physiol (Oxf) 2018;222:e12923. https://doi.org/10.1111/apha.12923.

25. Waheed A, Sly WS. Carbonic anhydrase XII functions in health and disease. Gene 2017;623:33-40. 
26. Inagaki T, Moschetta A, Lee YK et al. Regulation of antibacterial defense in the small intestine by the nuclear bile acid receptor. Proc Natl Acad Sci U S A 2006;103:3920-3925.

27. Morgan PE, Pastoreková S, Stuart-Tilley AK, Alper SL, Casey JR. Interactions of transmembrane carbonic anhydrase, CAIX, with bicarbonate transporters. Am J Physiol Cell Physiol 2007;293:C738-C748.

28. Jeong YS, Hong JH. Governing effect of regulatory proteins for $\mathrm{cl}(-) / \mathrm{HCO} 3(-)$ exchanger 2 activity. Channels (Austin). 2016;10:214-224. https://doi.org/10.1080/19336950.2015.11340 68.

29. Orlowski A, De Giusti VC, Morgan PE, Aiello EA, Alvarez BV. Binding of carbonic anhydrase IX to extracellular loop 4 of the NBCe1 na+/HCO3- cotransporter enhances NBCe1-mediated HCO3- influx in the rat heart. Am J Physiol Cell Physiol 2012;303:C69-80. https://doi.org/10.1152/ajpcell.00431.2011.

30. Liskova V, Hudecova S, Lencesova L et al. Type 1 sodium calcium exchanger forms a complex with carbonic anhydrase IX and via reverse mode activity contributes to $\mathrm{pH}$ control in hypoxic tumors. Cancers (Basel) 2019;11:1139. https://doi.org/10.3390/ cancers 11081139 .

31. Armstrong D, Bennett JR, Blum AL et al. The endoscopic assessment of esophagitis: a progress report on observer agreement. Gastroenterology 1996;111:85-92.

32. Mastracci L, Spaggiari P, Grillo F et al. Microscopic esophagitis in gastro-esophageal reflux disease: individual lesions, biopsy sampling, and clinical correlations. Virchows Arch 2009;454:3139. https://doi.org/10.1007/s00428-008-0704-8.

33. Schneider NI, Plieschnegger W, Geppert $\mathrm{M}$ et al. Validation study of the esohisto consensus guidelines for the recognition of microscopic esophagitis (histoGERD trial). Hum Pathol 2014;45:994-1002.

34. Rubio CA, Ichiya T, Schmidt PT. Lymphocytic oesophagitis, eosinophilic oesophagitis and compound lymphocytic-eosinophilic oesophagitis I: histological and immunohistochemical findings. J Clin Pathol 2017;70:208-216. https://doi.org/10.1136/jclin path-2016-203782.

35. Dellon ES, Liacouras CA, Molina-Infante J, et al. Updated international consensus diagnostic criteria for eosinophilic esophagitis: Proceedings of the AGREE conference. Gastroenterology. 2018;155:1022-1033.e10

36. Viikila P, Kivela AJ, Mustonen $\mathrm{H}$ et al. Carbonic anhydrase enzymes II, VII, IX and XII in colorectal carcinomas. World $J$ Gastroenterol 2016;22:8168-8177. https://doi.org/10.3748/wjg. v22.i36.8168.

37. Pastorekova S, Parkkila S, Parkkila AK et al. Carbonic anhydrase IX, MN/CA IX: analysis of stomach complementary DNA sequence and expression in human and rat alimentary tracts. Gastroenterology 1997;112:398-408.

38. Karhumaa P, Parkkila S, Tureci O et al. Identification of carbonic anhydrase XII as the membrane isozyme expressed in the normal human endometrial epithelium. Mol Hum Reprod 2000;6:68-74. https://doi.org/10.1093/molehr/6.1.68.

39. Parkkila AK, Parkkila S, Juvonen T, Rajaniemi H. Carbonic anhydrase isoenzymes II and I are present in the zona glomerulosa cells of the human adrenal gland. Histochemistry 1993;99:37-41. https://doi.org/10.1007/bf00268018.

40. McHugh ML. Interrater reliability: the kappa statistic. Biochem Med (Zagreb) 2012;22:276-282.

41. Tobey NA, Koves G, Orlando RC. Human esophageal epithelial cells possess an na+/H+ exchanger for $\mathrm{H}+$ extrusion. Am J Gastroenterol 1998;93:2075-2081.

42. Tobey NA, Reddy SP, Khalbuss WE, Silvers SM, Cragoe EJ, Orlando RC. $\mathrm{Na}(+)$-dependent and -independent cl-/HCO3exchangers in cultured rabbit esophageal epithelial cells. Gastroenterology 1993;104:185-195.
43. Shiozaki A, Hikami S, Ichikawa D et al. Anion exchanger 2 suppresses cellular movement and has prognostic significance in esophageal squamous cell carcinoma. Oncotarget 2018;9:2599326006. https://doi.org/10.18632/oncotarget.25417.

44. Shiozaki A, Kudou M, Ichikawa D et al. Expression and role of anion exchanger 1 in esophageal squamous cell carcinoma. Oncotarget 2017;8:17921-17935. https://doi.org/10.18632/oncotarget. 14900.

45. Laczko D, Rosztoczy A, Birkas K et al. Role of ion transporters in the bile acid-induced esophageal injury. Am J Physiol Gastrointest Liver Physiol 2016;311:G16-31. https://doi.org/10.1152/ajpgi. 00159.2015.

46. Park SY, Lee YJ, Cho EJ, Shin CY, Sohn UD. Intrinsic resistance triggered under acid loading within normal esophageal epithelial cells: NHE1- and ROS-mediated survival. J Cell Physiol 2015;230:1503-1514. https://doi.org/10.1002/jcp.24896.

47. Cao L, Yuan Z, Liu M, Stock C. (Patho-)physiology of na(+)/H(+) exchangers (NHEs) in the digestive system. Front Physiol 2020;10:1566. https://doi.org/10.3389/fphys.2019.01566.

48. Becskeházi E, Korsós MM, Erőss B, Hegyi P, Venglovecz V. OEsophageal ion transport mechanisms and significance under pathological conditions. Front Physiol 2020;11:855. https://doi. org/10.3389/fphys.2020.00855.

49. Fitzgerald RC, Omary MB, Triadafilopoulos G. Altered sodium-hydrogen exchange activity is a mechanism for acidinduced hyperproliferation in barrett's esophagus. Am J Physiol 1998;275:G47-55. https://doi.org/10.1152/ajpgi.1998.275.1.G47.

50. Siddique I, Khan I. Regulation of na/H exchanger-1 in gastroesophageal reflux disease: possible interaction of histamine receptor. Dig Dis Sci 2003;48:1832-1838. https://doi.org/10.1023/a: 1025503318409.

51. Kivilaakso E. Inhibition of gastric mucosal carbonic anhydrase by taurocholic acid and other ulcerogenic agents. Am J Surg 1982;144:554-557.

52. Boone CD, Tu C, McKenna R. Structural elucidation of the hormonal inhibition mechanism of the bile acid cholate on human carbonic anhydrase II. Acta Crystallogr D Biol Crystallogr 2014;70:1758-1763. https://doi.org/10.1107/S13990047140074 57.

53. Kusterer K, Szabo S. Gastric mucosal protection by acetazolamide derivatives: Role of carbonic anhydrase and sulfhydryls. Eur J Pharmacol 1987;141:7-13.

54. Pan Q, Nicholson AM, Barr $\mathrm{H}$ et al. Identification of lineageuncommitted, long-lived, label-retaining cells in healthy human esophagus and stomach, and in metaplastic esophagus. Gastroenterology 2013;144:761-770. https://doi.org/10.1053/j.gastro.2012. 12.022 .

55. Takahashi H, Suzuki Y, Nishimura J et al. Characteristics of carbonic anhydrase 9 expressing cells in human intestinal crypt base. Int J Oncol 2016;48:115-122. https://doi.org/10.3892/ijo.2015. 3260 .

56. Saarnio J, Parkkila S, Parkkila AK et al. Immunohistochemical study of colorectal tumors for expression of a novel transmembrane carbonic anhydrase, MN/CA IX, with potential value as a marker of cell proliferation. Am J Pathol 1998;153:279-285.

57. Cheng H, Leblond CP. Origin, differentiation and renewal of the four main epithelial cell types in the mouse small intestine. V. Unitarian theory of the origin of the four epithelial cell types. Am J Anat. 1974;141:537-561. https://doi.org/10.1002/aja.10014 10407.

58. Zhang HY, Zhang $X$, Chen $X$ et al. Differences in activity and phosphorylation of MAPK enzymes in esophageal squamous cells of GERD patients with and without barrett's esophagus. Am J Physiol Gastrointest Liver Physiol 2008;295:G470-G478. https:// doi.org/10.1152/ajpgi.90262.2008. 
59. Eltzschig HK, Carmeliet P. Hypoxia and inflammation. $N$ Engl J Med 2011;364:656-665. https://doi.org/10.1056/NEJMra0910 283.

60. Huo X, Agoston AT, Dunbar KB et al. Hypoxia-inducible factor- $2 \alpha$ plays a role in mediating oesophagitis in GORD. Gut 2017;66:1542-1554. https://doi.org/10.1136/gutjnl-2016-312595.

61. Pawlik MW, Kwiecien S, Pajdo R et al. Esophagoprotective activity of angiotensin-(1-7) in experimental model of acute reflux esophagitis. Evidence for the role of nitric oxide, sensory nerves, hypoxia-inducible factor-1alpha and proinflammatory cytokines. J Physiol Pharmacol 2014;65:809-822.

62. Wagner BA, Venkataraman S, Buettner GR. The rate of oxygen utilization by cells. Free Radic Biol Med 2011;51:700-712. https://doi.org/10.1016/j.freeradbiomed.2011.05.024.

63. Jovov B, Van Itallie CM, Shaheen NJ et al. Claudin-18: a dominant tight junction protein in Barrett's esophagus and likely contributor to its acid resistance. Am J Physiol Gastrointest Liver Physiol 2007;293:G1106-G1113.

64. Oshima T, Koseki J, Chen X, Matsumoto T, Miwa H. Acid modulates the squamous epithelial barrier function by modulating the localization of claudins in the superficial layers. Lab Invest 2012;92:22-31. https://doi.org/10.1038/labinvest.2011.139.

65. Barnett DH, Sheng S, Charn TH et al. Estrogen receptor regulation of carbonic anhydrase XII through a distal enhancer in breast cancer. Cancer Res. 2008;68:3505-3515. https://doi.org/10.1158/ 0008-5472.CAN-07-6151.

66. Zentilin P, Savarino V, Mastracci L et al. Reassessment of the diagnostic value of histology in patients with GERD, using multiple biopsy sites and an appropriate control group. Am J Gastroenterol 2005;100:2299-2306.

67. Tanimoto T, Takeda M, Nasu M et al. Immunohistochemical coexpression of carbonic anhydrase II with Kv1.4 and TRPV1 in rat small-diameter trigeminal ganglion neurons. Brain Research 2005;1044(2):262-265.

68. Casini A, Caccia S, Scozzafava A, Supuran CT. Carbonic anhydrase activators. The selective serotonin reuptake inhibitors fluoxetine, sertraline and citalopram are strong activators of isozymes I and II. Bioorg Med Chem Lett. 2003;13:2765-2768.

69. Temperini C, Scozzafava A, Puccetti L, Supuran CT. Carbonic anhydrase activators: X-ray crystal structure of the adduct of human isozyme II with L-histidine as a platform for the design of stronger activators. Bioorg Med Chem Lett 2005;15:5136-5141.

70. Vistoli G, Aldini G, Fumagalli L, Dallanoce C, Angeli A, Supuran CT. Activation effects of carnosine- and histidine-containing dipeptides on human carbonic anhydrases: a comprehensive study. Int J Mol Sci 2020;21:1761. https://doi.org/10.3390/ijms210517 61.

Publisher's Note Springer Nature remains neutral with regard to jurisdictional claims in published maps and institutional affiliations. 